\title{
Snow stability during rain
}

\author{
H. CONWAY AND G. F. RAYMOND \\ Geophysics Program AK-50, University of Washington, Seattle, Washington 98195, U.S.A.
}

\begin{abstract}
The mechanical response of snowpacks to penetrating liquid water was observed over two winter seasons in the central Cascade Mountains, Washington, U.S.A. Following the onset of rain, three evolutionary regimes of snow behavior were identified: immediate avalanching, delayed avalanching, and return to stability. Immediate avalanching occurred within minutes to an hour after the onset of rain and the time of release could be predicted with an accuracy of less than an hour from meteorological forecasts of the transition from snow to rain. These avalanches usually slid on surfaces substantially deeper than the level to which water or associated thermal effects had penetrated. The mechanism by which alteration of a thin skin of surface snow can cause deep slab failure has not been identified, but several possibilities involving a redistribution of stress are discussed. Delayed avalanches released several hours after rain started. The delay varied, depending on the rate of increasing stress associated with the additional precipitation, and on the time taken for water to penetrate and weaken a potential sliding layer. It is difficult to define accurately the evolving distribution of liquid water in snow which makes it difficult to predict accurately the time of avalanching. Depth profiles of the rate of snow settlement showed that a wave of increased strain rate propagated into the snow in response to penetrating water. This type of measurement could prove useful for predicting when snow stability is reaching a critical condition. Avalanche activity was rare after continuation of rain for $15 \mathrm{~h}$ or more. This return to stability occurred after drainage structures had evolved and penetrated the full depth of the snowpack. Established drain channels route water away from potential sliding surfaces and are also relatively strong structures within a snowpack.
\end{abstract}

\section{INTRODUCTION}

Rain on snow is a major cause of mid-winter avalanches in maritime climates (Conway and others, 1988; Heywood, 1988) and spring avalanches caused by meltwater are common (Ambach and Howorka, 1966; Kattelmann, 1984). Processes relating to the evolution of snow texture during wetting are well understood (Raymond and Tusima, 1979; Colbeck, 1986), and the weakening of snow from melting or rain is expected in terms of the grain-scale physics (Colbeck, 1982). However, it is still uncertain how macro-scale mechanical behavior of a snowpack is related to micro-scale processes. The response is complicated because of the layered stratigraphy of snowpacks (Colbeck, 1991) and also because liquid water does not penetrate snow uniformly (Wakahama, 1975; Colbeck, 1979, Marsh and Woo, 1984).

In this paper we discuss the effects of liquid-water penetration on the evolution of snow texture and stratigraphy, and on the timing of avalanche release.

\section{FIELD OBSERVATIONS}

Concurrent observations of avalanche activity, snow properties and weather were made in the Cascade Mountains near Snoqualmie Pass, Washington, U.S.A. during the winters of 1987-88 and 1988-89. Eight major rain-on-new-snow events occurred during this period and accessory information is available from the local avalanche-control effort that has been in operation since 1973.

The terrain near Snoqualmie Pass lies between 900 and $1700 \mathrm{~m}$ and mid-winter rain is common at these elevations. A typical snowpack contains a relatively homogeneous base $2-3 \mathrm{~m}$ deep that has settled and grain-coarsened during one or more episodes of rain. Storms deposit up to $1 \mathrm{~m}$ of new snow and subsequent rain often causes some or all of the storm snow to avalanche.

\section{Timing of avalanche cycles}

The timing of avalanche activity during rain depends on the evolution of the mechanical properties of the snowpack which is partly controlled by the volume and rate of water influx. Figure la shows the number and timing of avalanche cycles in relation to the time that rain started and Figure $1 \mathrm{~b}$ shows the amount of precipitation that had fallen as rain when each of the avalanche cycles occurred. The potential for avalanche release was highest a few minutes after rain started and before $1 \mathrm{~mm}$ of rain had accumulated. During continued rain, avalanche cycles occurred at various times up to $13 \mathrm{~h}$ after rain had started. After that time activity decreased, indicating a return to stability. In all cases the return to stability 

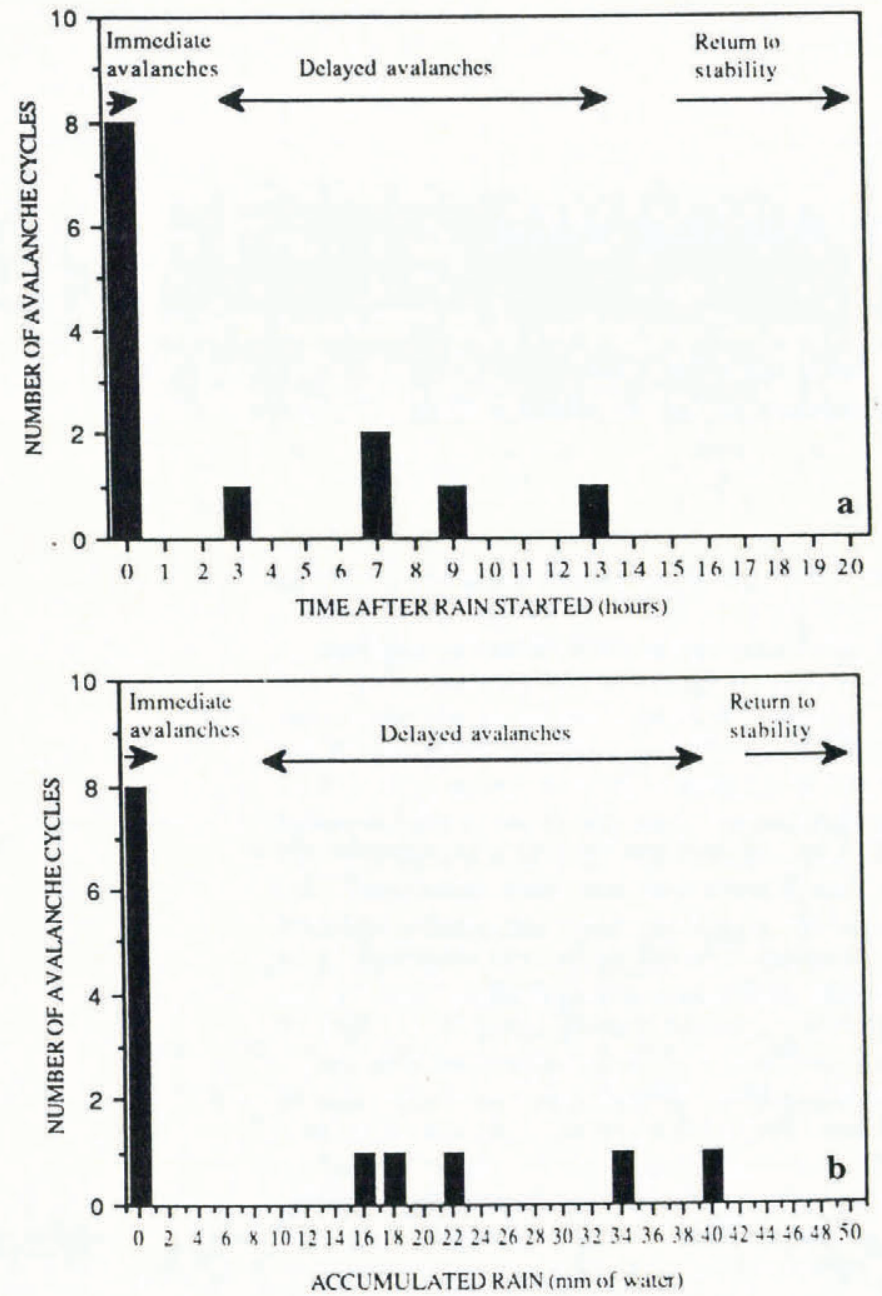

Fig. 1. a. The number and timing of avalanche cycles in relation to the time that rain started. $b$. The amount of precipitation that had fallen as rain when each of the avalanche cycles occurred. These data are from the eight rain-on-new-snow events that occurred during the winters of $1987-88$ and $1988-89$.

occurred after less than $40 \mathrm{~mm}$ of rain had fallen on the snow.

Based on these observations we distinguish three types of behavior during rain-on-snow events: immediate avalanches, which release minutes after rain starts; delayed avalanches, which release more than $1 \mathrm{~h}$ after rain starts; and a return to stability, which occurs $10-20 \mathrm{~h}$ after rain has started. Below we describe specific observations during rain-on-snow events.

\section{Immediate avalanching}

Hourly measurements, starting on 9 January 1988, of air temperatures at 1160 and $915 \mathrm{~m}$, and precipitation at $915 \mathrm{~m}$ are shown in Figure 2. A temperature inversion occurred when a warm, westerly frontal system over-rode cold air trapped at the surface and this caused rain to start first at higher elevations and later at lower elevations.

Avalanche activity began soon after rain started; avalanches released first at higher elevations and later at lower elevations (Fig. 2). A snow profile near the lower starting zones two hours before the warm-up showed that $18 \mathrm{~cm}$ of new snow (medium grain-size, very low
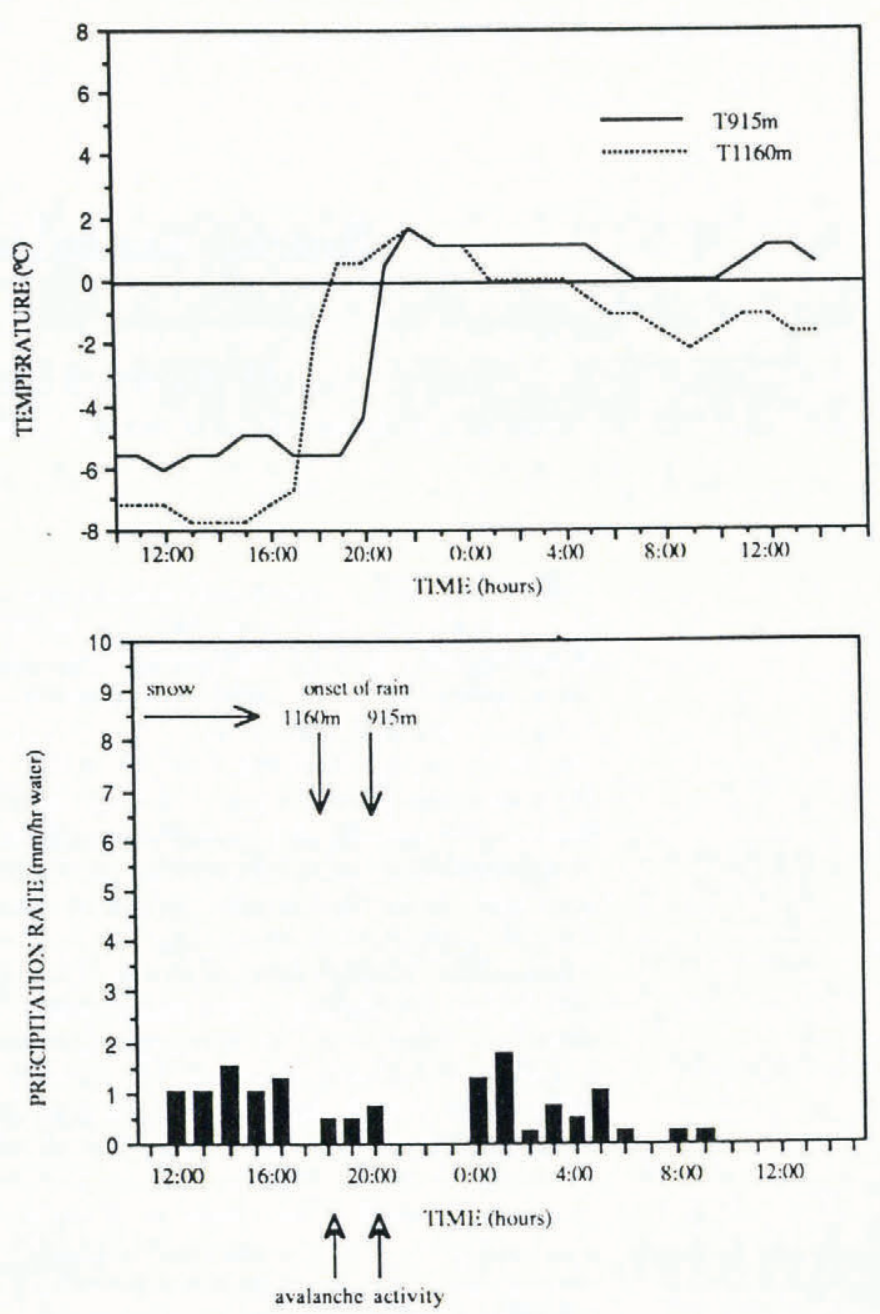

Fig. 2. Hourly measurements of air temperature at 915 and $1160 \mathrm{~m}$ and precipitation at $915 \mathrm{~m}$ starting at $1000 \mathrm{~h} 9$ Fanuary 1988. Closed arrows show the timing of avalanche activity, starting first at high elevations $(1100 \mathrm{~m})$ where warming first started, and then two hours later at lower elevations $(980 \mathrm{~m})$. The timing follows the time that rain started at the respective starting zones.

hardness) had been deposited on stratified, partly metamorphosed snow (well-bonded and medium hardness). Deeper in the snowpack ( $40 \mathrm{~cm}$ below the surface), grains had coarsened during a previous wetting cycle and the snow hardness was high. One might expect loose snow avalanches soon after rain water had weakened snow near the surface and slab avalanches some time later after water had penetrated and weakened a sub-surface layer. However, in this case the immediate avalanches were slabs 20-30 cm deep which slid on top of the well-bonded, partly metamorphosed snow. In general, although some immediate avalanches released as loose slides, it was not uncommon for them to be slabs a few decimeters or more thick.

\section{Delayed avalanching}

Rain started at $1300 \mathrm{~h}$ on 4 April 1989 and many slabs up to $30 \mathrm{~cm}$ deep released immediately even although less than $0.25 \mathrm{~mm}$ of rain had accumulated (Fig. 3). A second avalanche cycle occurred $13 \mathrm{~h}$ later on slopes which had not been controlled with explosives. The delayed avalanches were large (class $3+$ ), wet slabs up to $1 \mathrm{~m}$ deep. Prior to the rain, a snow profile at a site several 

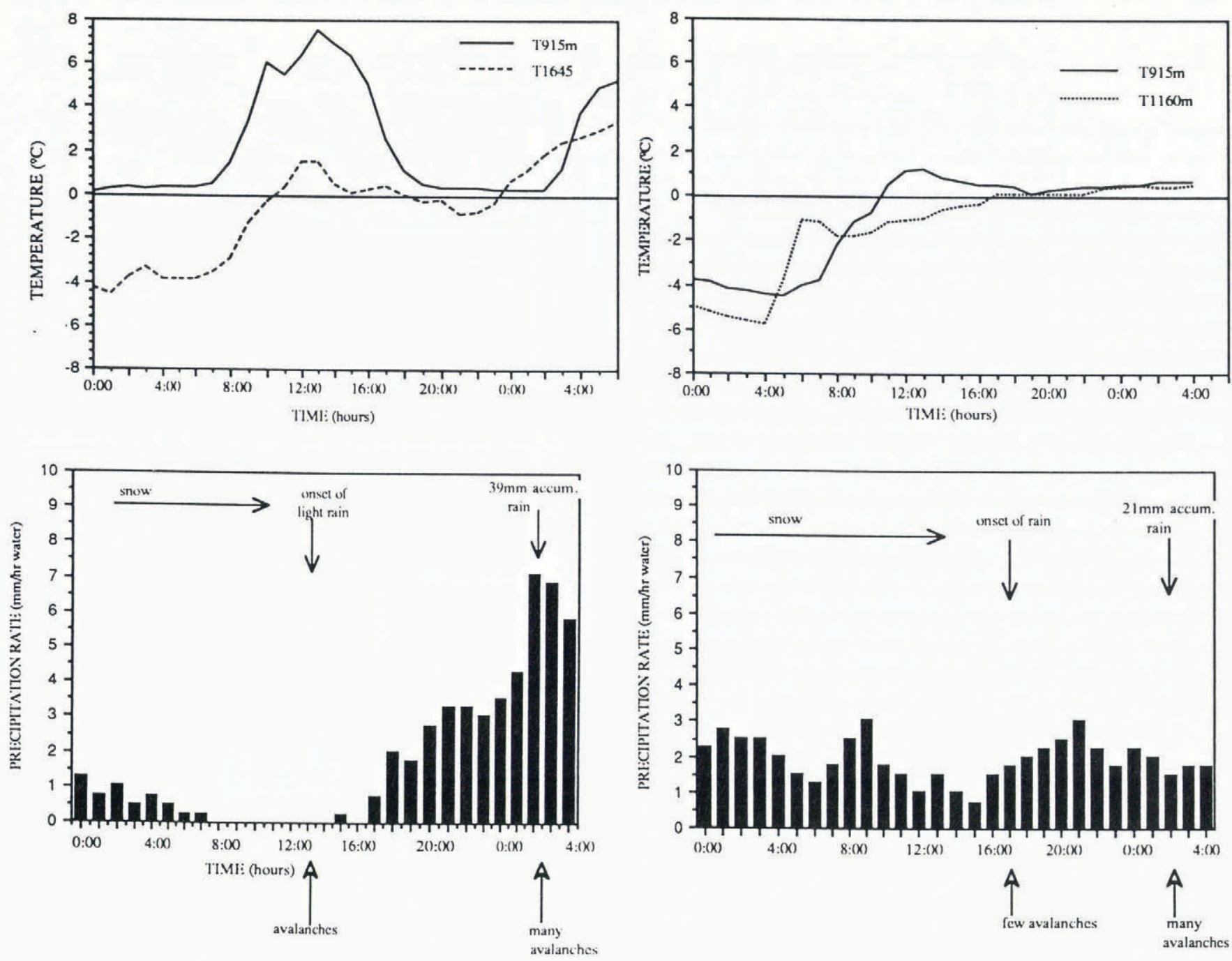

Fig. 3. Hourly measurements of air temperature at 915 and $1645 \mathrm{~m}$ and precipitation at $915 \mathrm{~m}$ starting at midnight on 4 April 1989. Closed arrows show timing of avalanche activity that occurred first when precipitation changed to rain, and again $13 \mathrm{~h}$ later.

kilometers east of the major activity showed $11 \mathrm{~cm}$ of new snow (low hardness) which overlay layers of partly metamorphosed snow (medium hardness). A $2 \mathrm{~cm}$ layer of coarse, poorly bonded grains (low hardness) existed $52 \mathrm{~cm}$ below the surface. Grains deeper in the snowpack had coarsened from a previous rain event and were wellbonded (high hardness). Although detailed fracture-line profiles are not available, avalanche technicians observed that only the recent new snow (low hardness) avalanched immediately, and the delayed avalanches slid on top of the old coarse-grained snow.

During another storm shown in Figure 4, few avalanches released when rain started, but nine hours later several large (class 3) wet slabs up to $40 \mathrm{~cm}$ deep released on slopes which had not previously been controlled. This storm was on 15 January 1989 and, although the air temperature had warmed $8 \mathrm{~h}$ before precipitation changed to rain at $1700 \mathrm{~h}$, it had remained below freezing. These conditions would allow the nearsurface snow to settle and gain strength, and probably helped to minimize immediate activity. The sliding surface for the delayed avalanches was within the storm
Fig. 4. Hourly measurements of air temperature at 915 and $1160 \mathrm{~m}$ and precipitation at $915 \mathrm{~m}$ starting at midnight on 14 January 1989. Closed arrows show timing of minor avalanche activity that occurred as precipitation changed to rain, and major avalanche activity $9 \mathrm{~h}$ later.

snow; snow deposited early in the storm had stabilized and did not avalanche.

\section{Return to stability}

An additional $63 \mathrm{~mm}$ of rain fell after the delayed avalanches on 5 April (Fig. 3), but no avalanches released naturally. The snowpack was apparently stable after $13 \mathrm{~h}$ and $39 \mathrm{~mm}$ of water influx. The timing of the return to stability was not unique; $13 \mathrm{~h}$ is the longest time we have recorded. In other cases the snow stabilized more rapidly and after less liquid water influx. For example on 15 January 1989, no avalanches released after $7 \mathrm{~h}$ of rain and $21 \mathrm{~mm}$ of water influx (Fig. 4), and on 14 January 1988 , a return to stability occurred after $8 \mathrm{~h}$ and $34 \mathrm{~mm}$ of water (Fig. 6).

A return to stability during continued rain has also been observed at Milford in New Zealand where avalanche activity usually decreases after about $20 \mathrm{~h}$ of rain (Conway, 1990). We are not certain what volumes of water throughput are required to achieve stability in that area, but both snow accumulation and rates of precipitation are higher than those at Snoqualmie Pass. 


\section{Penetration of moisture and heat}

Moisture and heat alter the shape and texture of grains which affect the mechanical properties of the snow. We tracked the progress of water through snow by spreading water-soluble dye at the surface and then excavating snow pits at different times during rain events. In cases where the snow had been previously wetted, the dye usually penetrated the full depth of a snowpack $(2 \mathrm{~m}$ or more) within a few minutes. However when rain fell on new snow, water penetrated only the upper $5-10 \mathrm{~cm}$ in the first hour. Penetration to greater depths began as "flow fingers" which were about $1 \mathrm{~cm}$ in diameter and 2$20 \mathrm{~cm}$ apart. Soon after fingering began, water flowed preferentially through a few of the fingers which enlarged at the expense of others. The evolution of larger flow structures could take up to ten hours and by that time they were typically $20-30 \mathrm{~cm}$ in diameter, and $0.5-2 \mathrm{~m}$ apart and, in many cases, penetrated the full depth of the snowpack. The diameter of the channels continued to increase during additional rainfall and after $24-48 \mathrm{~h}$ they had usually coalesced, which made the entire snowpack coarse-grained and relatively homogeneous.

The surface topography of the snow changed during water infiltration. Moisture in the snow increases the rate of densification and so snow within a channel settles faster than the dry snow outside a channel. Undulations developed at the surface as a result of the differential settlement and their wavelength was determined by the spacing of the channels. When the channels enlarged, the amplitude of the undulations decreased and the surface became smooth again when the snowpack was homogeneous.

Several processes feed back positively during the evolution of drain channels. In granular materials water flows preferentially along a path that is already wet. This tendency is enhanced further in snow because the presence of liquid water causes grain-growth which increases the permeability to water flow; undulations at the surface effectively route any surface water towards the hollows which feed into existing flow channels.

Water often flowed laterally through sub-surface layers as well as downward through vertical channels. Sub-surface lateral spreading of water usually occurred within layers that were initially low-density snow or at stratigraphic boundaries where a fine-grained layer overlay coarse-grained snow. This is in contrast with a more common perception that water spreads across the upper surface of impermeable ice crusts (Perla and Martinelli, 1976). The permeability of ice is controlled by veins which exist at grain boundaries, and vein size increases rapidly as the ice temperature increases above $-0.1^{\circ} \mathrm{C}$ (Langham, 1974, 1975). The temperature of ice in direct contact with liquid water will be close to $0^{\circ} \mathrm{C}$ and in our experience ice crusts had little effect on the downward percolation of water.

The temperature profile of a snowpack delineates zones at the melting point and the potential presence of liquid water. A three-dimensional array is required for a more complete picture of the temperature distribution and such measurements are planned for the future. In this study we obtained one-dimensional profiles by allowing a vertical line of thermistors to be buried by snowfalls.
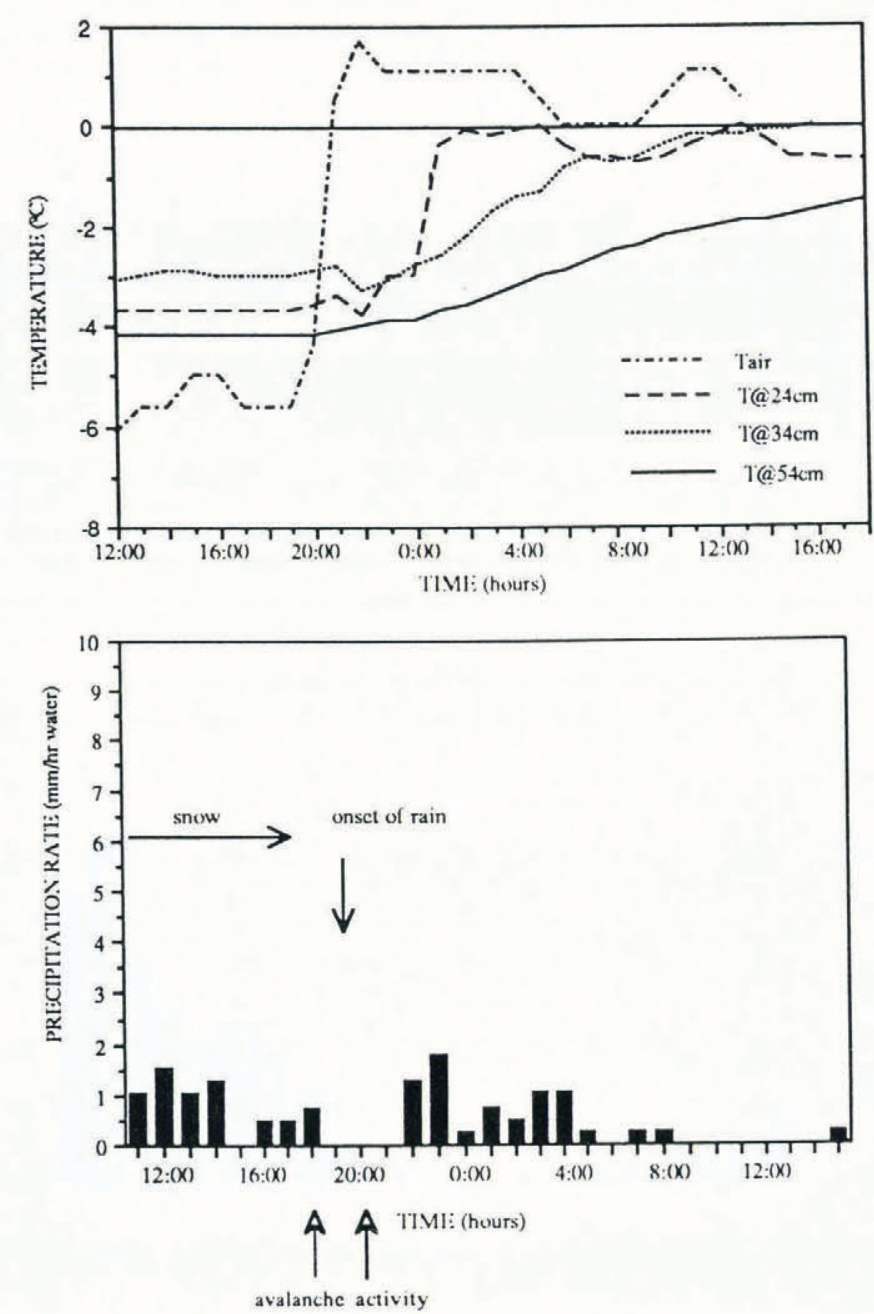

Fig. 5. Hourly measurements at $915 \mathrm{~m}$ of air and snow temperatures and precipitation starting at noon on 9 January 1988. Thermistors were buried 24, 34 and $54 \mathrm{~cm}$ below the surface. Major avalanche activity (marked by the closed arrow) occurred at the onset of rain but snow temperatures did not warm significantly until about four hours later.

Figure 5 shows hourly measurements of precipitation, air and snow temperatures at $915 \mathrm{~m}$. Measurements start on 9 January 1988 which is the same event described in Figure 2. Rain started at $2000 \mathrm{~h}$ when the air temperature increased above $0^{\circ} \mathrm{C}$, but temperatures 24,34 and $54 \mathrm{~cm}$ below the surface did not increase until four hours later at midnight (Fig. 5). The slabs which released minutes after rain started were $20-30 \mathrm{~cm}$ deep and the temperature profile suggests that the avalanches released before water had penetrated to the sliding layer. It is possible that water did penetrate to the sliding layer through a channel and the signal was missed by the measurements, but there was no evidence of that happening.

Figure 6 shows other measurements of air temperature and snow temperatures 15,25 and $40 \mathrm{~cm}$ below the surface. Rain started at $0330 \mathrm{~h}$ on 14 January 1988 and numerous slabs up to $40 \mathrm{~cm}$ deep avalanched immediately. Again the temperature profile suggests that water and associated thermal effects had penetrated less than $15 \mathrm{~cm}$ into the snow at the time of release. $7 \mathrm{~h}$ later a second avalanche cycle occurred and by this time the thermal wave had penetrated at least $40 \mathrm{~cm}$ (Fig. 6). We 

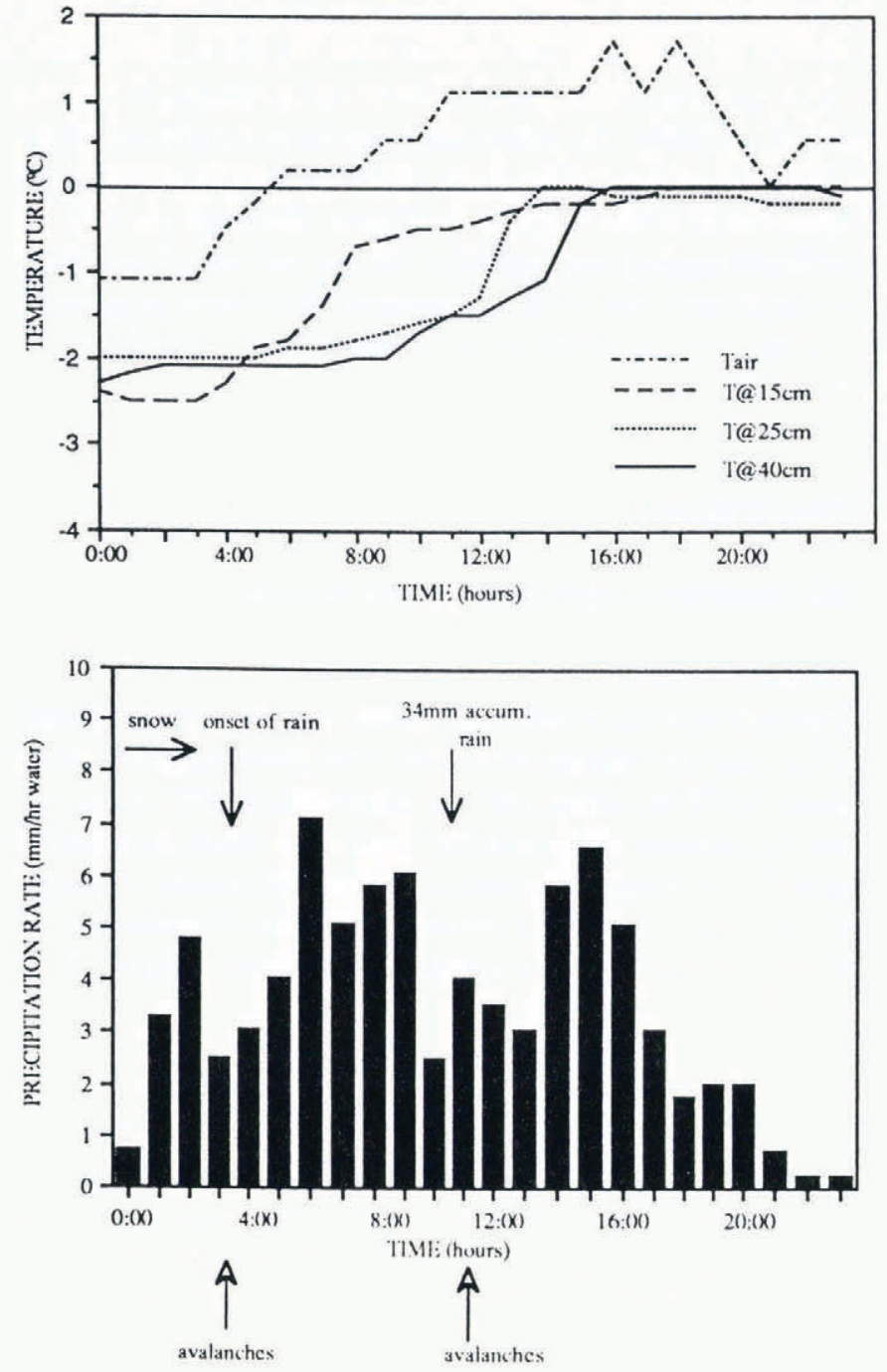

Fig. 6. Hourly measurements at $915 \mathrm{~m}$ of air and snow temperatures and precipitation starting at midnight on 14 January 1988. Thermistors were buried 15, 25 and $40 \mathrm{~cm}$ below the surface. Closed arrows mark the timing of avalanche activity which occurred at the onset of rain, and again $8 \mathrm{~h}$ later. Snow temperatures were well below freezing when avalanches first released, but warming had started when the second avalanche cycle occurred.

do not have a temperature profile at the starting zone, which was about $100 \mathrm{~m}$ higher than the study site, but it is likely that liquid water had penetrated to the sliding surface by the time the delayed avalanches released. Avalanche activity decreased about $8 \mathrm{~h}$ after rain had started and before all the snow was at $0^{\circ} \mathrm{C}$; apparently homogeneity of the snowpack is not a necessary condition for a return to stability during rain-on-snow events.

\section{Settlement profile}

The rate of snow settlement is influenced by the additional weight of the rain as well as metamorphic processes associated with the penetration of moisture and heat. We expect the rate of settlement will increase when snow is first wetted and decrease as grains round and become closely packed. Depth profiles of settlement in a horizontal snowpack were obtained from the vertical velocity of shoes which were buried at different depths.
Velocity was measured by running a cord vertically up from a shoe to a rotary potentiometer suspended above the snow surface. The system worked well except for some short-term disturbances caused by winds buffeting the cord which caused intervals of no apparent movement until the snow settled sufficiently to take up slack in the cord. The shoes, which were $8 \mathrm{~cm} \times 8 \mathrm{~cm}$ square perforated plastic sheets, were set at the surface at different times during snowstorms. This procedure minimized disturbances to the snow and to subsequent water percolation. Vertical strain rate was derived from velocity differences between shoes. The pattern of water infiltration causes differential settlement and so a threedimensional array of shoes would offer a more complete picture. In our one-dimensional set-up the shoes were not aligned directly above each other, which complicates interpretation of the measurements because one shoe may respond to a local perturbation that does not affect a nearby shoe. Another limitation of the experimental procedure was that shoes were set manually at convenient times; it would be better to make measurements with closer depth resolution.

Figure 7 shows profiles of the vertical velocity and strain rate in a level snowpack starting on 4 April 1989. Very light rain (less than $0.25 \mathrm{~mm} \mathrm{~h}^{-1}$ ) started at $1300 \mathrm{~h}$ and at that time shoes were located at the surface, and also below the surface at depths of 18 and $38 \mathrm{~cm}$. We have not smoothed these velocity profiles and we suspect that the short-term fluctuations in the velocity measurements at $38 \mathrm{~cm}$ reflect disturbances from wind or snow falling on the cord. The snow deeper than $38 \mathrm{~cm}$ had been soaked by rain during a previous warming and had graincoarsened. Snow between 18 and $38 \mathrm{~cm}$ had partially settled but had not been wetted, and the most recent snow $(0$ to $18 \mathrm{~cm})$ was low density $\left(\rho=70 \mathrm{~kg} \mathrm{~m}^{-3}\right)$. When rain started, this recent snow settled rapidly (faster than $16 \mathrm{~mm} \mathrm{~h}^{-1}$ ), but velocities deeper in the snowpack (at 18 and $38 \mathrm{~cm}$ ) remained less than $4 \mathrm{~mm} \mathrm{~h}^{-1}$. In fact, the deeper shoes did not begin to show a mechanical response to the rain until $8 \mathrm{~h}$ later. The velocity at $18 \mathrm{~cm}$ reached a maximum of $8 \mathrm{~mm} \mathrm{~h}^{-1}$ at $0145 \mathrm{~h}$ on 5 April $(12.25 \mathrm{~h}$ after rain started), and the velocity at $38 \mathrm{~cm}$ reached a maximum of $6 \mathrm{~mm} \mathrm{~h}^{-1}$ at $0245 \mathrm{~h}$. The strain rate between 18 and $38 \mathrm{~cm}$ reached a maximum of about $0.02 \mathrm{~h}^{-1}$ at $0230 \mathrm{~h}$ on 5 April which was $13 \mathrm{~h}$ after the onset of rain. Rates of settlement decreased after that and by $0600 \mathrm{~h}$ on 5 April ( $17 \mathrm{~h}$ after rain had started), the strain rate at all depths was less than $0.005 \mathrm{~h}^{-1}$ (Fig. 7). Excavations at $0900 \mathrm{~h}$ on 5 April showed that all shoes were located within a channel where the snow had densified $(\rho=440$ $460 \mathrm{~kg} \mathrm{~m}^{-3}$ ) and grain-coarsened (1-2 mm diameter). The snow-surface topography was undulating with a wavelength of 1-1.5 m; between the channels the snow was still dry and fine-grained.

The evolution of snow stability during this storm was discussed earlier (Fig. 3). The most recent snow (equivalent to the upper $18 \mathrm{~cm}$ at this site) avalanched immediately rain started. $13 \mathrm{~h}$ later, delayed avalanches slid to the depth of the coarse-grained snow (38 cm deep at this site), and then activity decreased. Although the avalanches started from zones where conditions may have been different from those at the study site, these three stages of mechanical evolution are evident in the 

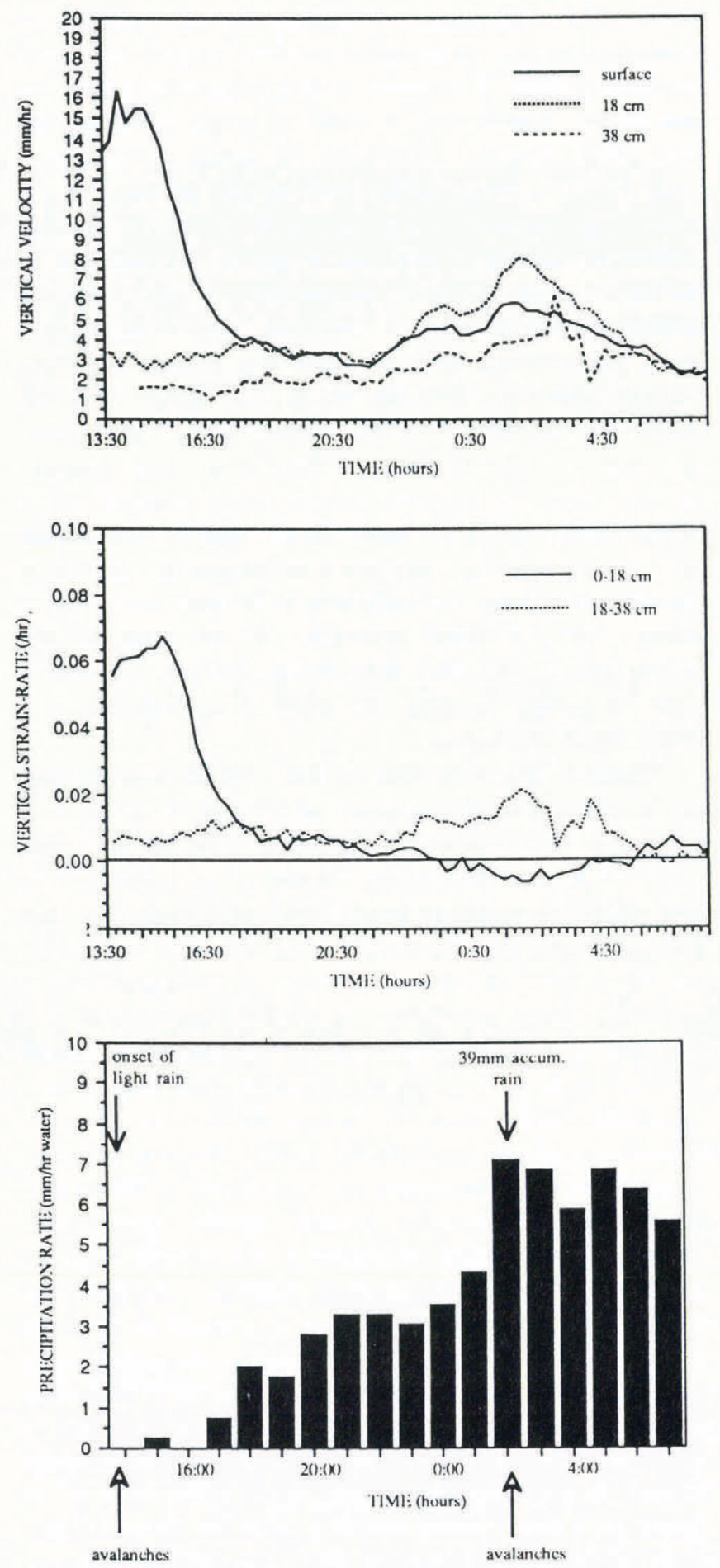

Fig. 7. Vertical velocity, strain-rate and precipitation measurements made in a level snowpack during 4-5 April 1989. Velocity and strain-rate measurements were obtained from shoes at the surface, and below the surface at $18 \mathrm{~m}$ and $38 \mathrm{~cm}$. Closed arrows show the timing of avalanche activity that occurred first when precipitation changed to rain and again $13 \mathrm{~h}$ later.

settlement profile. Vertical strain rate was high at the snow surface during the initial instability, and high later at depth when the delayed avalanche cycle occurred. Strain rates were decreasing when observations indicated that avalanche activity had decreased.

About $10 \mathrm{~h}$ after rain started, the vertical velocity at $18 \mathrm{~cm}$ exceeded the velocity at the surface and this condition existed for the next $5 \mathrm{~h}$ (Fig. 7). This condition could be a result of differential settlement as discussed earlier or, alternatively, the cohesion of the moist surface snow may have increased sufficiently to bridge the snow below partially. In other cases we have excavated snow beneath a moist surface layer and observed that the moist layer could often support itself over distances up to $1 \mathrm{~m}$ without sagging appreciably. We are not sure if bridging is important, but it is conceivable that stress generated during the collapse of a bridge could contribute to instability.

\section{DISCUSSION}

\section{Mechanical response of snow to rain}

\section{Immediate response}

The potential for avalanche release is highest immediately after rain first falls on new snow. The avalanches are often slabs $30-50 \mathrm{~cm}$ deep and yet observations and measurements indicate that moisture and heat have penetrated only 5-10 cm into the snow at the time of release. Changes at the surface must somehow alter the distribution of stress deeper in the snowpack and cause failure. This could occur in several ways:

Gravitational loading. Precipitation rate in the area is usually less than $10 \mathrm{~mm} \mathrm{~h}^{-1}$ which would increase the average down-slope shear stress on a $30^{\circ}$ slope by about $50 \mathrm{~Pa} \mathrm{~h}^{-1}$. Locally, the stress might increase more than this, but it is unlikely that all immediate avalanches release as a result of such small increases of average stress.

Inertial loading. Small surface avalanches or snow falling from trees impose inertial loads that could cause deeper slab release. In some cases we have seen evidence of such disturbances but in many cases we have not.

Redistribution of longitudinal stress. A loss of tensile strength over part of a slab could be significant in situations where the strength of the slab was critical for maintaining stability. A partial loss of strength could increase the tensile stress sufficiently to cause tensile failure of the remaining slab. For example, a complete loss of strength in the upper $10 \mathrm{~cm}$ of a $30 \mathrm{~cm}$ slab could increase the longitudinal stress in the lower $20 \mathrm{~cm}$ by up to $50 \%$.

Water could weaken the surface of a slab by decreasing the strength of bonds between grains which relieves longitudinal stress by creep. Alternatively, high capillary forces active in moist snow could generate high tensile stress by pulling grains against boundary constraints. This stress would be transient but might be sufficient to cause tensile cracks which would decrease the strength of the moist surface snow.

At this point we cannot distinguish between these alternative mechanisms that might weaken the surface snow. Settlement of the snow would also decrease the 
cross-section over which longitudinal force is supported and raise the stress. This process would probably result in a compensatory strengthening of the slab as it densified and would not necessarily destabilize a snowpack.

Observations suggest that immediate avalanching occurs only if the snow stability before rain is already close to critical. For example, snowpacks that have had time to strengthen during a slow warm-up are less susceptible to immediate instability. In many cases a snowpack will not respond to artificial control before rain starts and yet it will avalanche naturally soon after the onset of rain (personal communication from C. Wilbour). It has been suggested that a potential slab avalanche contains zones of basal weakness and zones of basal pinning and that fracture can be initiated by a localized perturbation at a trigger zone (Conway and Abrahamson, 1984; Gubler and Bader, 1989). An explosion or a skier might impose a locally large perturbation but might miss a critical zone. Rain affects all the snow surface more or less simultaneously and, although the amplitude of the perturbation may be small, it is far reaching and is likely to affect a critical zone if one does exist. The ubiquity of avalanches at the onset of rain implies that freshly deposited snow often contains at least one critical trigger zone which, when disturbed even at a low level, will initiate failure.

\section{Delayed response}

Stress evolves during continued rain as water adds weight to the snowpack and also penetrates and potentially weakens a sub-surface layer. It is thought that a zone of basal weakness extending over a few meters or more is required to initiate slab failure; this condition could develop when water spreads laterally along a sub-surface layer. Vertical penetration of water occurs through channels which are usually spaced less than $2 \mathrm{~m}$ apart, and this spacing would allow water to spread laterally over large basal areas almost simultaneously.

The presence of liquid water could weaken a snowpack in several ways:

Water causes melting at grain boundaries and bonds which reduces friction between grains.

Grains of new snow are often intricately shaped and the ratio of surface area to volume is large. Metamorphic processes are rapid in the presence of liquid water and grains change shape and texture rapidly. Although strength increases after grains have rounded and become closely packed, strength decreases during large textural changes. Further, we have observed a wave of increased rate of vertical strain which is associated with water penetrating into a horizontal snowpack. On slopes, vertical strain has a normal and a downslope shear component. A high rate of basal shear strain would contribute to instability (Gubler and Bader, 1989), and the slope normal component imposes a bending moment in the slab which may also contribute to instability.

\section{Return to stability}

Evidence from stratigraphic profiles, temperature profiles, and surface topography indicates that a return to stability occurs before the entire snowpack has become isothermal and homogeneous. Several factors contribute to increase stability during continued rainfall:

Avalanching will usually stabilize the snowpack remaining but this is not a necessary condition; we have often observed slopes stabilize without avalanching.

After drain channels have penetrated the full depth of a snowpack, subsequent water can pass directly through the snow and then it is less likely to accumulate and spread laterally at a sub-surface layer. Further, the snow within channels has densified, which makes the structure relatively strong, and the close spacing between channels interrupts the continuity of a potential shear layer. In most cases stability increases after drainage has been established, but in a few cases water might accumulate at the snow-ground interface and cause the release of fulldepth avalanches.

\section{Avalanche prediction}

The timing of avalanches that release immediately when rain starts can be predicted by forecasting meteorological conditions in the avalanche starting zones. A network of weather stations surrounding the starting zones and located in the tracks of approaching storms offers a means of forecasting the onset of rain at a specific site.

Accurate prediction of delayed avalanches is more problematical. It is difficult to define the time of release without specific knowledge of the snow stratigraphy and how the evolving spatial distribution of liquid water will affect its strength. In our experience, the delay varied up to $13 \mathrm{~h}$ after rain started, but longer delays have been observed in situations when the snowpack was deep and had not been wetted previously (personal communication from S. Breyfogle).

\section{CONGLUSIONS}

Substantial depths of new snow often avalanche at the onset of rain. Evidence from stratigraphic, temperature and velocity profiles at that time indicates that these avalanches release before moisture or heat have penetrated more than a few centimeters into the snow. The release mechanism for this type of avalanche does not require liquid water to penetrate and weaken a basal layer.

During continued rain the potential for avalanche release can remain high for $10-20 \mathrm{~h}$. This type of instability is controlled by the stresses which evolve as a result of liquid water penetrating the snowpack. Water penetration occurs through vertical channels that occupy only a small part of the snowpack. Water is sometimes diverted from a vertical channel and may flow laterally through a sub-surface layer or along a stratigraphic boundary. The presence of water weakens a layer either by melting grain contacts or by causing rapid textural changes within the snow. Snow stability decreases when the strength of a basal layer decreases. 
The length and diameter of channels increase with water influx and in time they penetrate the full depth of the snowpack. After drainage has been established, water is routed away from potential sliding surfaces and snow stability increases. Even during continued rain, avalanche release is rare after drainage through a snowpack has been established.

\section{ACKNOWLEDGEMENTS}

This research was supported by the U.S. Army Research Office and the Washington State Department of Transportation. C. Wilbour, S. Breyfogle, L. Reddon and J. Wilson (avalanche technicians at Snoqualmie Pass) assisted with the research.

\section{REFERENGES}

Ambach, W. and F. Howorka. 1966. Avalanche activity and free water content of snow at Obergurgl (1980 $\mathrm{m}$ a.s.l., spring 1962). International Association of Scientific Hydrology Publication 69 (Symposium at Davos 1965 - Scientific Aspects of Snow and Ice Avalanches), 65-72.

Colbeck, S. C. 1979. Water flow through heterogeneous snow. Cold Reg. Sci. Technol., 1(1), 37-45.

Colbeck, S. C. 1982. An overview of seasonal snow metamorphism. Rev. Geophys. Space Phys., 20(1), 45-61.

Colbeck, S. C. 1986. Statistics of coarsening in water-saturated snow. Acta Metall., 34(3), 347-352.

Colbeck, S. C. 1991. The layered character of snow covers. Rev. Geophys., 29(1), 81-96.
Conway, H. 1990. Review of avalanche program on SH 94, New Zealand. Dunedin, New Zealand, Transit New Zealand. (Technical Report.) Conway, H. and J. Abrahamson. 1984. Snow stability index. F. Glaciol., 30(106), 321-327.

Conway, H., S. Breyfogle and C. Wilbour. 1988. Observations relating to wet snow stability. In Proceedings International Snow Science Workshop, Whistler, 211-222.

Gubler, H. and H.-P. Bader. 1989. A model of initial failure in slabavalanche release. Ann. Glaciol., 13, 90-95.

Heywood, L. 1988. Rain on snow avalanche events - some observations. In Proceedings International Snow Science Workshop, Whistler, 125-136.

Kattelmann, R. C. 1984. Wet slab instability. In Proceedings International Snow Science Workshop, Aspen, Colorado, 102-108.

Langham, E. J. 1974. Phase equilibria of veins in polycrystalline ice. Can. F. Earth Sci., 11(9), 1280-1287.

Langham, E.J. 1975. The mechanism of rotting ice layers within a structured snowpack. International Association of Hydrological Sciences Publication 114 (Symposium at Grindelwald 1974-Snow Mechanics), 73-81.

Marsh, P. and M. Woo, 1984. Wetting front advance and freezing of meltwater within a snowcover. 1. Observations in the Canadian Arctic. Water Res. Resour., 20, 1853-1864.

Perla, R. I. and M. Martinelli, 1976. Avalanche handbook. Fort Collins, CO, U.S. Department of Agriculture. Forest Service. (Agriculture Handbook 489.)

Raymond, C.F. and K. Tusima. 1979. Grain coarsening of watersaturated snow. F. Glaciol., 22(86), 83-105.

Wakahama, G. 1975. The role of meltwater in densification processes of snow and firn. International Association of Hydrological Sciences Publication 114 (Symposium at Grindelwald 1974-Snow Mechanics), 66-72.

The accuracy of the references in the text and in this list are the responsibility of the authors, to whom queries should be addressed. 